\title{
Vitiligo: Skin Malignancies and Tumor Suppressive Marker P53
}

\section{Khalifa E Sharquie ${ }^{1^{*}}$, Adil A Noaimi ${ }^{1}$, Adel R Bandar ${ }^{2}$ and Salah Y Mohsin ${ }^{3}$}

${ }^{1}$ Scientific Council of Dermatology and Venereology-Iraqi and Arab Board for Medical Specializations, Department of Dermatology and Venereology, College of Medicine, University of Baghdad, Baghdad, Iraq

${ }^{2}$ Teaching Laboratories, Baghdad, Medical City, Baghdad, Iraq

${ }^{3}$ Department of Dermatology \& Venereology, Baghdad Teaching Hospital, Baghdad, Iraq

*Corresponding author: Professor Khalifa E Sharquie, Scientific Council of Dermatology \&Venereology-Iraqi Board for Medical Specializations, Department of Dermatology \& Venereology, College of Medicine, University of Baghdad, Medical Collection Office, P.O. Box 61080 Postal Code 12114, Baghdad, Iraq, Tel: 00964-7901468515; Fax: 009641-5372193; E-mail: ksharquie@ymail.com

Rec date: May 03, 2014; Acc date: May 23, 2014; Pub date: May 25, 2014

Copyright: ( ) Sharquie KE et al. 2014. This is an open-access article distributed under the terms of the Creative Commons Attribution License, which permits unrestricted use, distribution, and reproduction in any medium, provided the original author and source are credited.

\begin{abstract}
Background: Vitiligo is common autoimmune pigmentary disorders where there are no cutaneous cancers have been reported among affected patients.

Objective: To estimate the frequency P53 marker and its role in protection against skin cancers in patients with vitiligo.

Patients and Methods: This study took place in the Department of Dermatology, Baghdad Hospital during the period from May 2009-September 2010. It is composed of two parts: Part I was case descriptive study performed to record any association of skin malignancies in 300 vitiligo patients, 155 females and 145 males, while Part II was case observational, controlled, histochemical, investigative study to estimate the frequency of P53 in vitiliginous skin and adjacent normal skin in comparison with control group. Skin biopsies were taken from 25 patients, one from the centre of vitiliginous patch and the other about $0.5 \mathrm{~cm}$ adjacent to the patch (normal skin). Skin biopsies were also done for 25 individuals as a control group.
\end{abstract}

Results: Regarding Part I of the study, no malignant skin diseases like basal cell carcinoma, squamous cell carcinoma or malignant melanoma were found in the present work. In Part II of this work, the positivity of P53 in normal skin was $32 \%$, while in adjacent normal skin was $84 \%$ and in vitiliginous skin was $96 \%$.

Conclusions: P53 marker is over expressed in vitiligo skin and this might give it protection against skin cancers.

Keywords: Vitiligo; Skin malignancies; P53 marker; Iraq

\section{Introduction}

Vitiligo is an acquired disorder characterized by progressive, patchy loss of pigmentation from skin, overlying hair, and oral mucosa. The de-pigmented patches result from loss of melanocytes from the involved areas, apparently on an autoimmune basis [1]. P53 has many anticancer mechanisms and plays a role in apoptosis, genetic stability, and inhibition of angiogenesis [2]. Normal type p53 act as a control to prevent cells with damaged DNA entering the cell cycle [3]. In vitiligo especially the generalized type, there is absence of melanin in the epidermis which is considered the most protective factor against solar radiation and skin cancers [4].

In prolonged observations for seeing hundreds patients of vitiligo, we didn't come across of any skin malignancies even in outdoor worker (Sharquie's personal observations). Even histopathological examination of the vitiligo skin in the exposed areas showed no increased photoaging features compared to adjacent normal skin. Furthermore surprisingly, there was no increased risk for photosensitivity disorders, like polymorphous light eruption, solar urticaria and acute actinic dermatitis [5]. This in comparison with albinism which is an inherited disease associated with absence of melanin, there is an increase in frequency of skin malignancies [6].

A most recent study showed that autoimmune diseases like pemphigus vulgaris and systemic lupus erythematous showed absence of skin malignancies among those patients although they had received a prolonged course of immunosuppressive therapy as a result of active immune surveillance in those patients [7]. Also, on a recent study, it was reported that the tumor suppressive marker p53 is increased among patients with vitiligo [8].

Accordingly, the aim of present work was to record the frequency of skin malignancies among vitiligo patients and to estimate P53 in vitiligo skin.

\section{Patients and Methods}

This study is carried out in the Department of Dermatology and Venereology-Baghdad Teaching Hospital during the period from May 2009-September 2010.

Formal consent was taken from each patient after full explanation about the goal and nature of the present work. Also, ethical approval was taken from the scientific council of Dermatology and Venereology-Iraqi Board for Medical Specializations. 
Page 2 of 4

This study composed of two parts: Part I was case, descriptive study to record any association of skin malignancies in 300 vitiligo patients (155 females and 145 males).

History was taken from each patient regarding: age, gender, duration and the diagnosis was clinically done with aid of Wood's light examination. Also, dermatological study was carried out to categorize the types of vitiligo and to detect any associated skin malignancies in vitiliginous and non vitiliginous skin.

Part II was case observational, controlled, histochemical, investigative study to estimate P53 in vitiliginous skin and adjacent normal skin in comparison with apparently healthy control group. Skin biopsies were taken from 25 patients with vitiligo 16(64\%) males and $9(36 \%)$ females. Two biopsies were done for each patient one from the centre of vitiliginous patch and the other about $0.5 \mathrm{~cm}$ adjacent to the patch so called normal skin. Skin biopsies were also taken from normal skin for 25 individuals' 15(60\%) males and 10(40\%) females, who attended to the Skin Department with non-relevant skin diseases as a control group; these non-relevant skin diseases were as follow: 6 neurodermatitis, 5 postinflammatary hyperpigmentation 8 cholinergic urticuria, 4 skin tags, 2 benign melanocytic nevus.

Most biopsies in both groups were taken from dorsal aspect of the exposed parts of extremities like: forearms, hands, legs and feet, except 4 biopsies were taken from lateral aspect of neck. All the biopsies were sent to the Teaching Labs - Medical City Teaching Hospital to estimate the P53 marker by immunohistochemistry using peroxidaseantiperoxidase technique [9].

A score for estimation of P53 positivity in this work was done $[10,11]$. In this score we depend on the percentage of nuclei of the epidermis that taken the stain of the reaction compared with total number of nuclei in the high power field (40x) according to the following method:
$0<5 \%$ of cells are positive (the positive result is shown by brown nuclei)

$$
1=5 \% \text { to }<10 \% \text { of cells are positive }
$$

$2=10 \%$ to $<25 \%$ of cells are positive

\section{$3=25 \%$ to $<50 \%$ of cells is positive}

$4=>50 \%$ of cells are positive $[10,11]$.

Digital photography was taken using SONY* Cyber-Shot T300 10.1 MP.

SPSS v.18 (statistical package for social sciences version 18) used for data input and analysis. Continuous variables presented as mean \pm SD (standard deviation) and discrete variables presented as numbers and percentages. Chi square test for independence is used to test the significance of association between discrete variables.

\section{Results}

Regarding Part I of the study, a total of 300 patients with vitiligo were enrolled in the present study, 155 females (51.6\%) and 145 males (48.3\%) with female to male ratio was 1.07:1.

Their ages ranged from 4 months-77 years with a median age 20 years (Table 1). The duration of the disease ranged from 2 months-70 years with a median duration 4 years. The clinical types of the disease were: $122(40.6 \%)$ patients generalized type, 83(27.6) acrofacial, $78(26 \%)$ focal, and 17(5.6\%) segmental type.

Family history of the disease in the first degree relatives was seen in $45(15 \%)$ patients. No malignant skin diseases like basal cell carcinoma, squamous cell carcinoma or malignant melanoma were found in the present work.

\begin{tabular}{|l|l|l|l|l|l|l|}
\hline Age of onset in years & Frequency of males & $\%$ & $\begin{array}{l}\text { Frequency } \\
\text { females }\end{array}$ & of & Total & $\%$ \\
\hline $0-9$ & 29 & $9.60 \%$ & 50 & $16.60 \%$ & 79 & $26.30 \%$ \\
\hline $10-19$ & 45 & $15 \%$ & 52 & $17.30 \%$ & 97 & $32.30 \%$ \\
\hline $20-29$ & 23 & $7.60 \%$ & 13 & $4.30 \%$ & 36 & $12 \%$ \\
\hline $30-39$ & 18 & $6 \%$ & 14 & $4.60 \%$ & 32 & $10.60 \%$ \\
\hline $40-49$ & 12 & $4 \%$ & 16 & $5.30 \%$ & 28 & $9.30 \%$ \\
\hline $50-59$ & 9 & $3 \%$ & 6 & $2 \%$ & 15 & $5 \%$ \\
\hline $60-69$ & 6 & $2 \%$ & 3 & $1 \%$ & 9 & $3 \%$ \\
\hline $70-79$ & 3 & $1 \%$ & 1 & $0.30 \%$ & 4 & $1.30 \%$ \\
\hline Total & 145 & $48.30 \%$ & 3 & $51.60 \%$ & 300 & $100 \%$ \\
\hline
\end{tabular}

Table 1: Showing the ages of onset and gender of 300 patients with vitiligo

Part II of the study: the ages of patients with vitiligo ranged from $25-46$ years with a mean \pm SD of $31 \pm 8.2$ years and duration of the disease ranged from 1-12 years with a mean \pm SD of $4 \pm 7.3$ years. Twelve (48\%) patients had generalized type, 11(44\%) acrofacial and $2(8 \%)$ focal. The ages of 25 individuals as a control group ranged from 20 -50 years with a mean \pm SD of $32 \pm 6$ years.
The frequency of individuals with positive P53 in normal control decreased with increase in the score. While in patients with vitiligo with positive $\mathrm{p} 53$, the frequency of patients increased with increase in the score.

The positivity of P53 in control normal skin was 32\%, in adjacent vitiligo normal skin was $84 \%$ while in vitiliginous skin was $96 \%$. 
Page 3 of 4

Accordingly the positivity is very high in vitiligo skin (Table 2). The intensity of score 4 was zero in normal control, $20 \%$ positive in normal adjacent vitiligo skin and was positive in $40 \%$ of vitiliginous skin.
Figures 1-3 showed the positivity of p53 marker in the nuclei epidermis of normal control, adjacent vitiligo normal skin and vitiliginous skin.

\begin{tabular}{|l|l|l|l|l|l|l|l|l|}
\hline P53 score & $\begin{array}{l}\text { Frequency of individuals with } \\
\text { normal skin(control) }\end{array}$ & $\begin{array}{l}\text { Frequency of patients } \\
\text { with adjacent vitigo } \\
\text { normal skin }\end{array}$ & $\begin{array}{l}\text { Frequency of patients } \\
\text { with vitiliginous skin }\end{array}$ & $\%$ & Chi-Square & P-values \\
\hline 0 & 17 & $68 \%$ & 4 & $16 \%$ & 1 & $4 \%$ & 27.92 & $<0.0001$ \\
\hline 1 & 7 & $28 \%$ & 4 & $16 \%$ & 3 & $12 \%$ & 2.28 & $>0.05$ \\
\hline 2 & 1 & $4 \%$ & 5 & $20 \%$ & 4 & $16 \%$ & 3 & $>0.05$ \\
\hline 3 & 0 & $0 \%$ & 7 & $28 \%$ & 7 & $28 \%$ & 8.1 & 0.013 \\
\hline 4 & 0 & $0 \%$ & 5 & $20 \%$ & 10 & $40 \%$ & 12.5 & $<0.001$ \\
\hline Total & 25 & & 25 & & 25 & & & \\
\hline
\end{tabular}

Table 2: The frequency of patients and individuals according to their P53 score

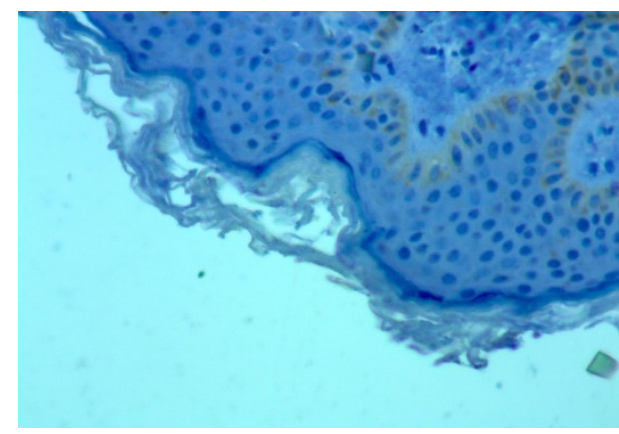

Figure 1: Showing the negative P53 in the nuclei of epidermis of normal control as no brown nuclei were seen.

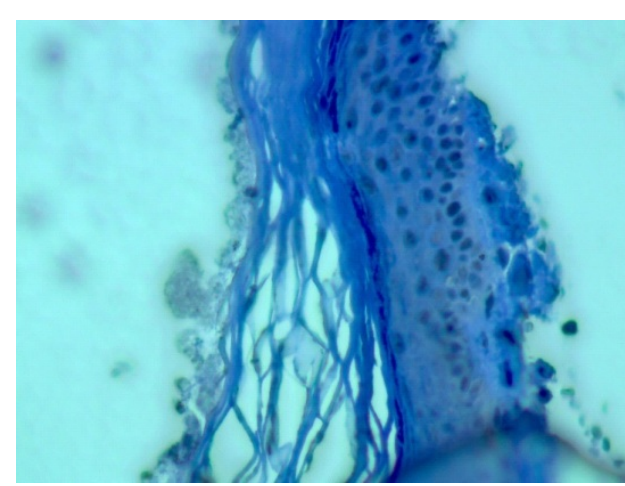

Figure 2: Showing the positivity of P53 in the nuclei of the epidermis in adjacent normal skin of patients with vitiligo seen as brown nuclei.

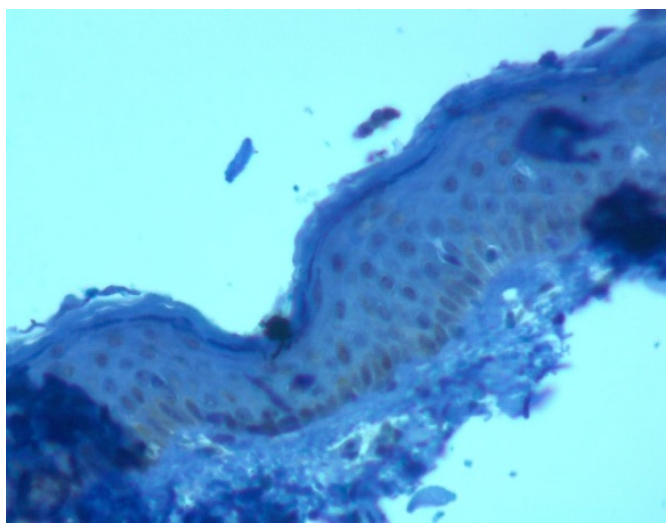

Figure 3: Showing the positivity of $\mathrm{P} 53$ in the nuclei of the epidermis in the vitiliginous skin of patients with vitiligo seen as brown nuclei.

\section{Discussion}

Vitiligo is a common autoimmune pigmentary disorder with a great cosmetic effect. It has been reported that vitiligo patients have a lower risk than general population to develop skin malignancies [5]. The present work had confirmed this observation as there were no skin malignancies like basal cell carcinoma, squamous cell carcinoma or malignant melanoma were found.

P53 is a tumor suppressive protein that protects cells anywhere in the body from undergoing malignant changes after injury by viruses, radiation, free radicals and others [2]. It had been found that this marker is over expressed in vitiliginous skin more than adjacent skin and more than the skin of healthy control. Also it had been observed that vitiligo skin is immune against sun burns and skin malignancies and this was well correlated with the presence of P53 [12].

In the present work, the frequency of individuals in normal control decreases with increase in the p53 score while in patients with vitiligo, the frequency of patients increases with increase in the score. The positivity of P53 in normal skin was 32\%, in adjacent vitiligo normal 
skin was $84 \%$ while in vitiliginous skin was $96 \%$. Also the score was zero in normal control while positive in $20 \%$ in the adjacent vitiligo normal vitiligo skin and positive in $40 \%$ of vitiliginous skin. So, the present work had confirmed the high positivity of P53 marker in vitiligo skin and its role in protection against skin cancers. A most recent study showed that autoimmune diseases like pemphigus are protective against skin malignancies in kidney transplant recipients [7] and as vitiligo is autoimmune disorder, it might also have such protection.

In conclusion, P53 marker is over expressed in vitiligo skin and this might give its protection against skin cancers.

\section{References}

1. Hann SK, Nordlund J (2000) Vitiligo, Blackwell Science, Oxford, UK.

2. Wikipedia, the free encyclopedia (2010) P53

3. Mackie RM (1998) Epidermal skin Tumours. Textbook of Dermatology (6thedn) London Black Well Publishing Company, UK 36:1654-5.

4. Fitzpatrick MDB, Ortonne TB, Hori Jp (1999) Hypomelanoses and Hypermelanoses. Fitzpatrick's Dermatology in General Medicine; 5th ed, 2; Data; 1999; 945-61.

5. Schallreuter KU, Tobin DJ, Panske A (2002) Decreased photodamage and low incidence of non-melanoma skin cancer in 136 sun-exposed caucasian patients with vitiligo. Dermatology 204: 194-201.
6. Lookingbill DP, Lookingbill GL, Leppard B (1995) Actinic damage and skin cancer in albinos in northern Tanzania: findings in 164 patients enrolled in an outreach skin care program. J Am Acad Dermatol 32: 653-658.

7. Sharquie KS, Noaimi AA, Al-Jobori AA (2013) Skin tumors and skin infections in kidney transplant recipients vs. patients with pemphigus vulgaris. International Journal of Dermatology:1-6.

8. van den Wijngaard RM, Aten J, Scheepmaker A, Le Poole IC, Tigges AJ, et al. (2000) Expression and modulation of apoptosis regulatory molecules in human melanocytes: significance in vitiligo. Br J Dermatol 143: 573-581.

9. Rosi and Ackrman s (2004) Surgical Pathology (9thedn) Library of Congress cataloging-in-publication data, USA 2:65-66

10. Gammon MD, Hibshoosh H, Terry MB, Bose S, Schoenberg JB, et al. (1999) Cigarette smoking and other risk factors in relation to p53 expression in breast cancer among young women. Cancer Epidemiol Biomarkers Prev 8: 255-263.

11. Apple SK, Hecht JR, Lewin DN, Jahromi SA, Grody WW, et al. (1999) Immunohistochemical evaluation of K-ras, p53, and HER-2/neu expression in hyperplastic, dysplastic, and carcinomatous lesions of the pancreas: evidence for multistep carcinogenesis. Hum Pathol 30: 123-129.

12. Schallreuter KU1, Behrens-Williams S, Khaliq TP, Picksley SM, Peters $\mathrm{EM}$, et al. (2003) Increased epidermal functioning wild-type p53 expression in vitiligo. Exp Dermatol 12: 268-277. 